\title{
Precipitation thresholds for drought recognition: a further use of the standardized precipitation index, SPI
}

\author{
J. F. Santos ${ }^{1}$, M. M. Portela ${ }^{2}$, M. Naghettini ${ }^{3}$, J. P. Matos ${ }^{2}$ \\ \& A. T. Silva ${ }^{2}$ \\ ${ }^{1}$ Escola Superior de Tecnoclogia e Gestão, ESTIG, Portugal \\ ${ }^{2}$ Instituto Superior Técnico, IST, Portugal \\ ${ }^{3}$ Universidade Federal de Minas Gerais, Brazil
}

\begin{abstract}
Most of the methods used to analyse drought episodes include drought indices associated with quantitative scales and which are based upon instrumental variables, with particular emphasis for precipitation. Among such indices, one of the most common indices, if not the most widely used, is the standardized precipitation index (SPI), which assigns a numerical value to the monthly precipitation or to the cumulative precipitation in groups of consecutive months. Such a value can be compared across regions with very distinct climates. Despite the widespread use of the SPI, the interpretation of its values and drought monitoring based on the same are by no means trivial tasks, particularly due to the fact that are standardized values which cannot be easily related with the precipitation records from which they derived. For this very reason, an additional calculation method has been developed which returns back to the precipitation field the SPI values for any drought threshold. By assigning the drought thresholds directly to precipitation the meaning of the SPI results are clearer and the identification and monitoring of the drought occurrences are more expedite. Based on the new concept developed for the SPI, precipitation surfaces that provide precipitation thresholds for drought recognition on a monthly basis and across different timescales throughout the Portuguese mainland are presented.

Keywords: detection and monitoring of droughts, precipitation thresholds for drought identification, inversion of the standardized precipitation index (SPI).
\end{abstract}




\section{Introduction: general concepts and primary data}

Precipitation is the most commonly instrumental variable used to detect and characterize drought occurrences due to the close connection between its temporal and spatial variability and the fresh water shortage and, consequently the drought episodes. In addition, precipitation is also widely monitored and long time samples are relatively common which confers more consistency to the hydrological characterisations based on such samples.

Over time, the constant maintenance of below average precipitation will cause a meteorological drought which, if prolonged, will progressively have effects on the level of the soil moisture deficit - agricultural drought, on the scarcity of surface water resources, including those stored in reservoirs and aquifers hydrological drought - and on the economical activity and social development in general - socioeconomic drought. Each of these latter three types of drought requires instrumental variables that aside from precipitation also enable the description of the phenomenon in its different aspects and interfaces with the sectors that are sensitive to it.

In recent years, a research focused on an extensive characterisation of droughts in mainland Portugal has begun, through the analysis of long term precipitation samples that so far included aspects such as the identification of homogeneous regions regarding the drought characteristics [1, 2], the application of specific procedures of statistical inference to those regions [3] and [4], the identification of the minimum network of rain gauges capable of characterizing the regional and temporal patterns of the phenomenon [5] and the development of models to hindcast the droughts at specific time scales [6].

Those studies have been supported by the monthly precipitation records compiled by [7] for a time span of 94 hydrologic years, from 1910/11 to 2003/04, in the 144 rain gauges evenly distributed throughout the country schematically located in Figure 1. In Portugal, the hydrologic years starts October $1^{\text {st }}$. The standardized precipitation index [8,9], SPI, was selected to characterize the occurrences of drought at different time scales.

SPI is one of the most used indices to evaluate and characterize droughts due essentially to: (i) its great flexibility because it may be applied at different time scales; (ii) its lower complexity of calculation comparative to other indices, as it is based on a well defined and relatively simple probabilistic model; (iii) its possible application to other hydro-climatological variables besides precipitation [10]; and (iv) its suitability to spatial representation and to drought comparison because it is a normalized index. An extensive review on the recognition of the aforementioned advantages of SPI and about some of their derived applications is provided in [1] and [2].

The time scales that are more frequently used for the SPI estimation are of 1 , 3, 6, 12 and 24 months (SPI1, SPI3, SPI6, SPI12 and SPI24, respectively), and it is generally agreed that the shorter time scales - up to 6 months - allow the assessment of meteorological and agricultural droughts, which are associated to precipitation and soil moisture deficits, respectively, and scales between 9 and 12 months, to hydrological drought, with water shortage reflected in the 
streamflows and in artificial lakes/reservoirs. The time scale of 24 months enables to assess the impact of the droughts on the aquifers that have a slower response due to their resilience.

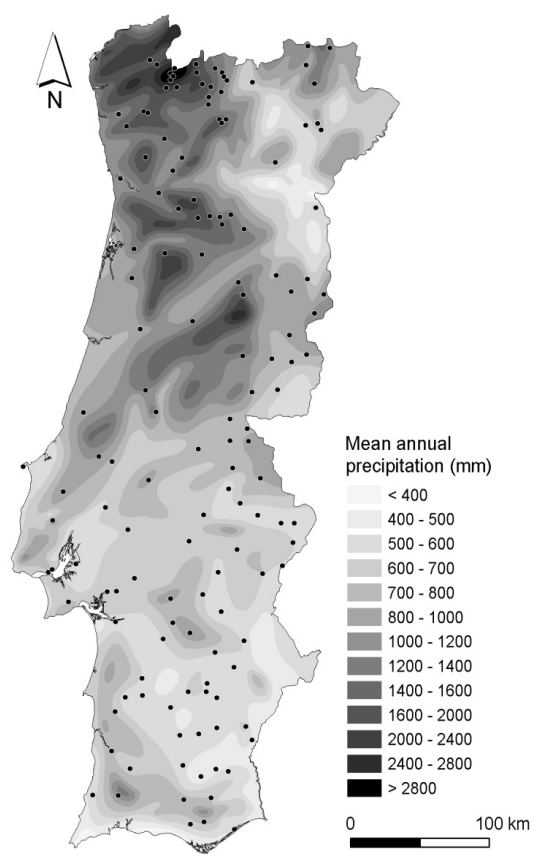

Figure 1: Mean annual precipitation in mainland Portugal. The dots represent the location of the 144 rain gauges utilized in this thesis reproduced from [1].

In essence, SPI gives a standardized measure of the precipitation deficit. Its calculation is based on long samples of monthly precipitation or of cumulative precipitation; typically, in 3, 6, 12 and 24 consecutive months, as referred to before.

For a given time scale (month or group of consecutive months) the calculation of SPI requires the adjustment of a probability distribution function to the corresponding sample of precipitation. The value of SPI attributed to each precipitation is no more than the z-standard normal associated to the probability of non-exceedance of that precipitation, according to the postulated distribution function.

The previous concept is depicted in Figure 2 for the application of the Pearson III law which is recommended by some authors as the more suitable one. In fact, originally, [9] adopted the Gamma distribution to calculate the SPI; later on some authors tested several statistical distributions based on different time scales and concluded that the distribution Pearson type III assured the best fit. This fact can be explained by the higher flexibility of the Pearson type III 
distribution given by its three parameters, in comparison with the Gamma distribution, with only two parameters $[8,11,12]$.
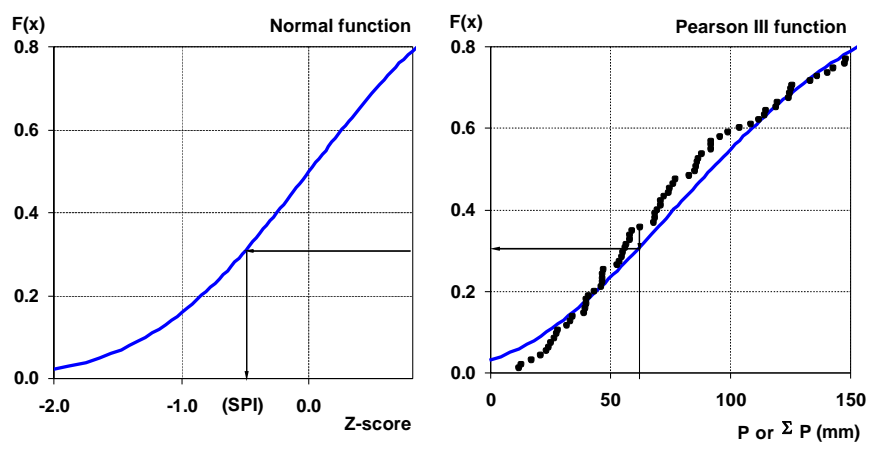

Figure 2: Schematic representation of the SPI calculation procedure adapted from [10].

It should be noted that the SPI calculation at a time scale of $\mathrm{k}$ months (with $\mathrm{k}>1$ ) requires that the precipitation records are constituted over a period of $\mathrm{N}$ hydrological years with record data over k consecutive months beginning in each month of the year. Each of the twelve samples thus obtained is treated as statistically independent from the other samples. For example, for $\mathrm{k}=3$ (i.e., SPI3), when working in hydrological year, the first of the previous samples refers to the cumulative precipitation from October to December over N-years period of records; the second, to the precipitation from November to January for that period and so forth. The result is that the two last cumulative precipitation samples in three months beginning in August (cumulative precipitation from August to October) and in September (cumulative precipitation from September to November) will have one less value (i.e., length of $\mathrm{N}-1$ ). The SPI values obtained by means of the statistical treatment of each of the successive samples are later included in a single series, which to some extent is continuous in time. In effect and continuing to use the previous example, the SPI3 estimated for the precipitation from January to March of a given year is followed by the SPI3 related to the precipitation that occurred between February and April of that same year, and so forth, notwithstanding the fact that each of the previous estimations resulted from the statistical treatment (done separately) of the precipitation at the time interval to which it refers over the record period, as mentioned before.

In the studies that support this paper, the calculation of the SPI series adopted the Pearson type III distribution function with parameters estimated by the Lmoments method, as proposed by [13] and [14] and extensively described in [15] and [10]. The drought categories considered were those proposed by [16], identified in Table 1, which also includes the non-exceedance probabilities associated to the same. 
For a given time scale, a value of the SPI of zero indicates that there was no deviations from the average precipitation at that time scale; a positive value indicates that the precipitation is higher than that average; a negative value indicates that precipitation is smaller than the same average and, if below certain thresholds, representative of drought episodes.

Table 1: $\quad$ Drought categories according to the SPI values [16].

\begin{tabular}{|c|c|c|}
\hline SPI & Drought category & Non-exceedance probability \\
\hline$>-0.84$ to $<0.84$ & Normal & $80.0 \%$ to $20.0 \%$ \\
$<-0.84$ & Moderate drought & $<20.0 \%$ \\
$<-1.28$ & Severe drought & $<10.0 \%$ \\
$<-1.65$ & Extreme drought & $<4.9 \%$ \\
\hline
\end{tabular}

\section{Methodology: a complementary use of the standardized precipitation index, SPI}

Despite the widespread use and the advantages of SPI compared with other drought indices, the interpretation of the values associated to SPI and drought monitoring based on those values are not easy to accomplish, especially because they involve standardized values that are difficult to relate with the precipitation from which mathematical manipulation they result.

Therefore, an additional calculation was developed that gives the SPI values that represent drought thresholds back to the precipitation field, thus facilitating an adequate interpretation of the meaning of such index and quite easily and reliably identifying the drought episodes [17]. As a result, monitoring can be operationalized as can the subsequent actions that need to be undertaken.

For that purpose and for all the 144 rain gauges of Figure 1, the monthly and the cumulative precipitation in 3, 6, 12 and 24 consecutive months were estimated for the values of SPI of -1.28 and -1.65 (severe and extreme drought, respectively, see Table 1 ). The previous estimation required the inversion of the SPI calculation procedure through the use of a set of widely tested computational subroutines [18] that were incorporated in a computational programme of drought analysis developed by the authors.

Figures 3 to 6 exemplify the results obtained by [17] for the drought threshold of -1.28 (severe drought) and for SPI1, SPI3, SPI6 and SPI12, respectively. It was not included a figure for SPI24 because such time scale is less pertinent regarding preventative drought monitoring. Also, the spatial pattern among months is quite similar.

Each one of the maps that is included in the previous figures shows the spatial distribution of the precipitation in given intervals of time - months or groups of months identified in the body of the map. Whenever the precipitation registered in a given location and period falls below the value shown by the map for such location and period, then the location is suffering a severe drought. Therefore, each map represents the surface of the minimum precipitation in a given interval of time below which an extreme drought episode is recognized - surfaces of monthly and cumulative precipitation thresholds for extreme drought. 


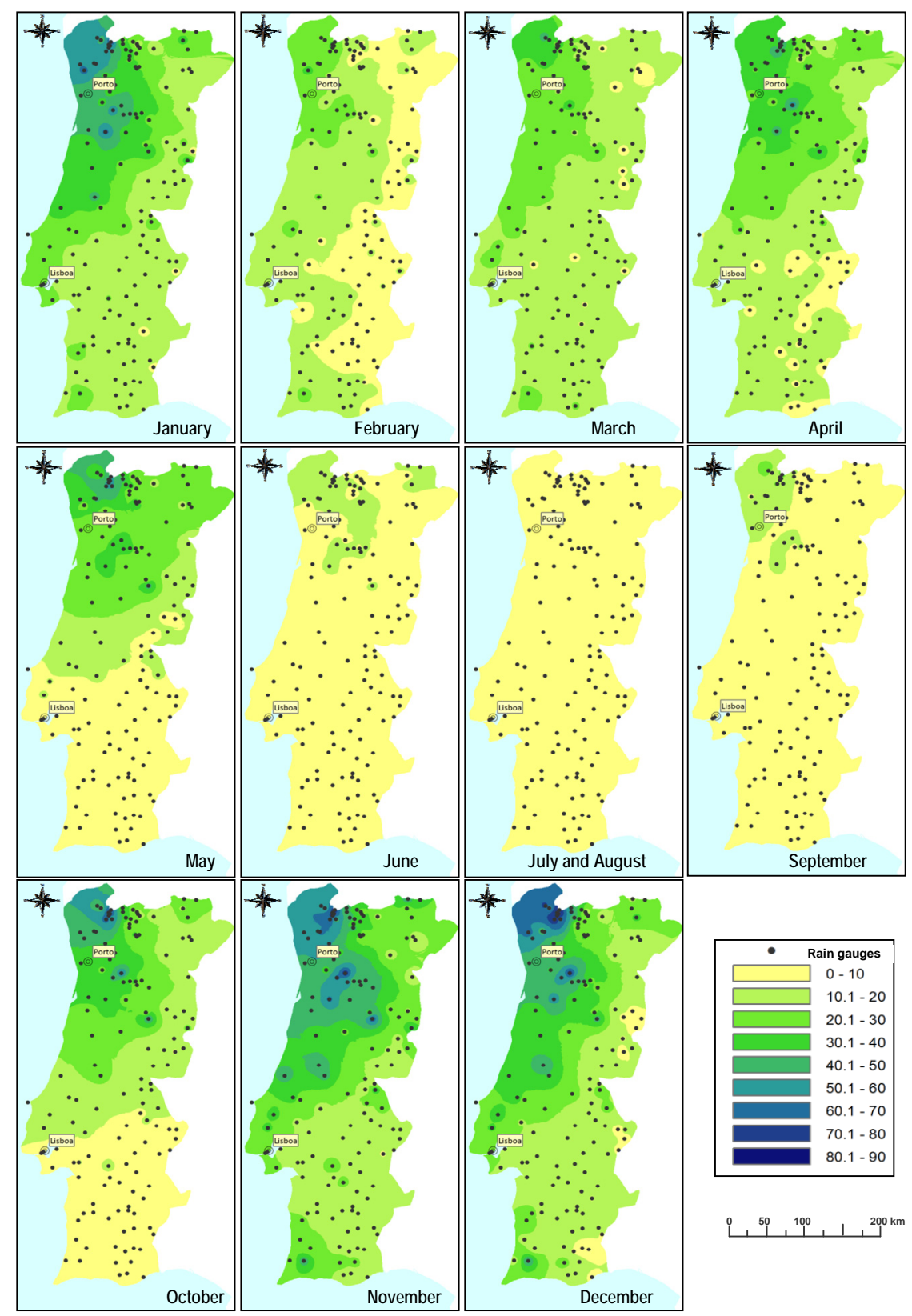

Figure 3: Inversion of SPI1=-1.28. Monthly precipitation corresponding to the severe drought threshold - adapted from [17]. 


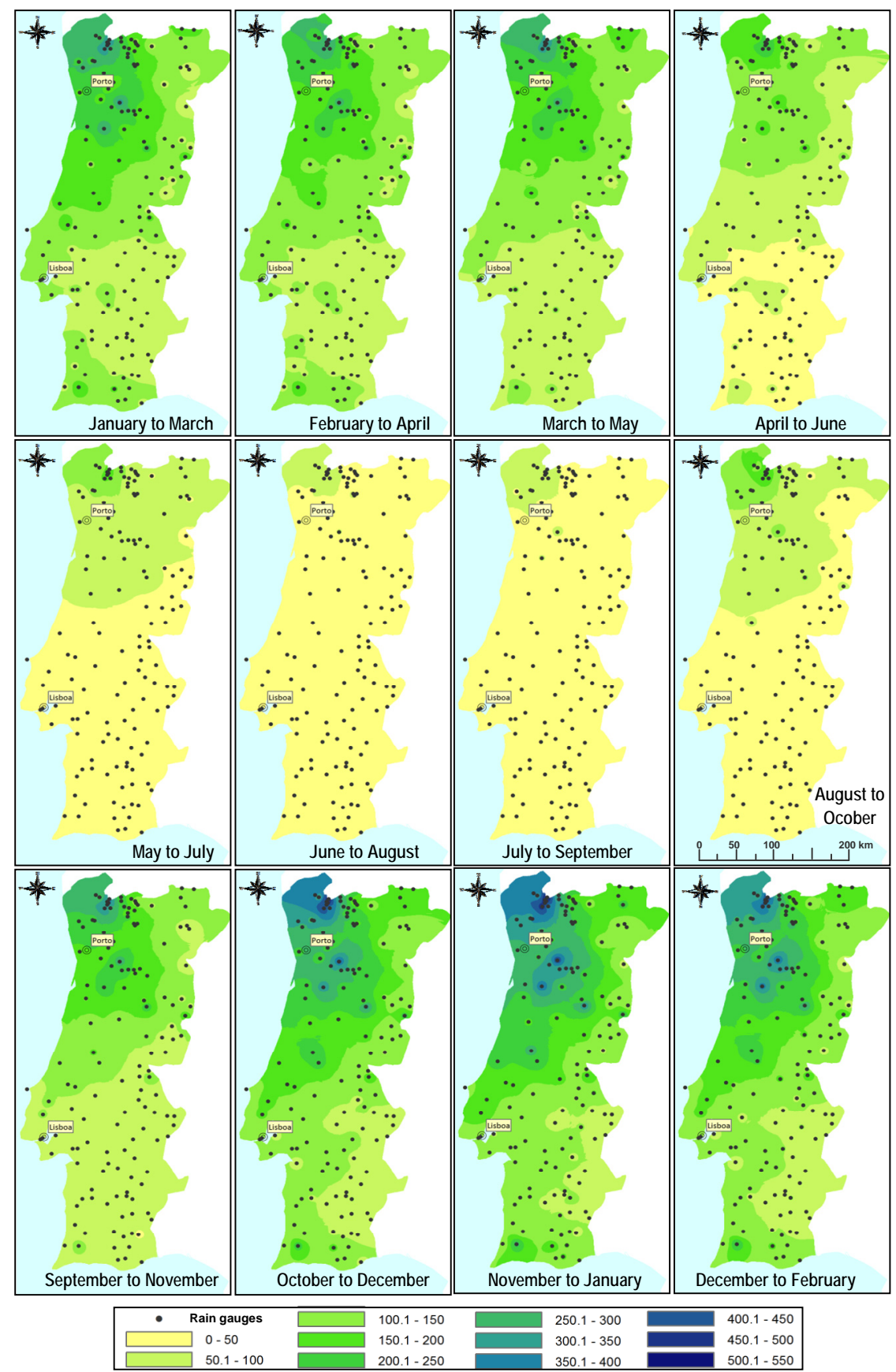

Figure 4: Inversion of SPI3 $=-1.28$. Precipitation in 3 consecutive months corresponding to the severe drought threshold - adapted from [17]. 


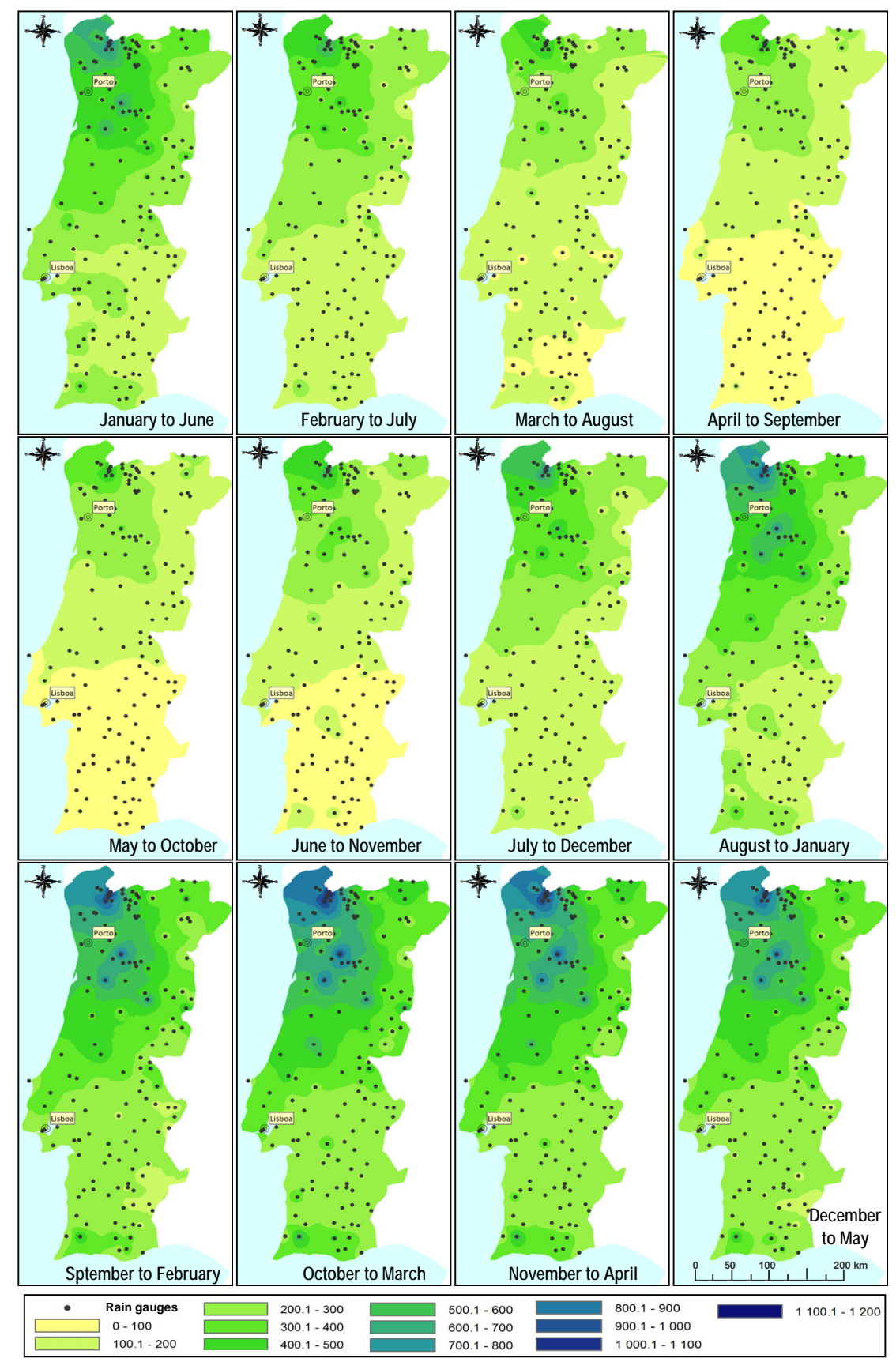

Figure 5: Inversion of SPI6=-1.28. Precipitation in 6 consecutive months corresponding to the severe drought threshold - adapted from [17]. 




Figure 6: Inversion of SPI12=-1.28. Precipitation in 12 consecutive months corresponding to the severe drought threshold - adapted from [17]. 
The precipitation surfaces were achieved by applying the IDW (Inverse Distance Weighting) spatial interpolation technique with exponent two to the precipitation thresholds obtained by the inversion of the SPI at different time scales in the 144 rain gauges that supported the study (Figure 1). The schematic localization of the gauges was also included in Figures 3 to 6.

To facilitate the reading, the maps included in each figure have an underlying organization that in some way refers to the civil year. Hence, on a monthly basis, Figure 3 provides month by month, the precipitation below which a severe drought occurs. As already mentioned, the remaining figures refer to the cumulative precipitation in $\mathrm{k}$ months (with $\mathrm{k}$ equal to three, six or twelve in correspondence with the SPI time scale, i.e., SPI3, SPI6 and SPI12), beginning in the successive months of civil year. This way, the result for each time scale (1, 3 , 6 or 12 months) is always 12 maps. The month or the period of consecutive months to which the precipitation thresholds refer is always identified in the body of each map.

Figure 3 shows that on a monthly time scale, there are large areas with monthly precipitation thresholds lower or equal to $10 \mathrm{~mm}$. Whilst the SPI time scale increases, the sequence of the maps that are included in each figure progressively highlights a spatial pattern of drought threshold precipitation that is poorly differentiated across these maps. This is particularly evident in the case of the larger time scale - Figure 6 obtained by inversion of SPI12 - which is explained by the fact that between each set of two consecutive maps, the cumulative period only differs by two months: the month at the beginning of the period which the first map refers to and the month at the end of the period to which the second map refers to.

It is interesting to note that within all the time scales analysed, the greater water availability that characterizes the coastal north-western region of Portugal results in relatively high monthly and cumulative precipitation thresholds. This fact derives from the concept which is associated to SPI that recognizes drought episodes by the deviations of the average precipitation and not by the own values of such precipitation.

\section{Conclusion}

Based on a drought characterization using the standardized precipitation index, SPI, a new application of this index is proposed. The results are surfaces of monthly and cumulative precipitation thresholds for drought recognition that provide month by month the thresholds of precipitation conducive to the identification of episodes of severe and extreme droughts in mainland Portugal. Although this papers only includes the results for a drought threshold of -1.28 (severe drought), maps equivalent to those of Figures 3 to 6 were obtained by [17] for the drought threshold of -1.65 (extreme drought) and are available at http://www.aprh.pt/rh/v33n2.html.

Additional studies are being developed aiming at quantifying, for any location and time scale, the probability of recovering from a drought event based on the 
comparison between the registered precipitation and the drought precipitation threshold for the same time scale.

\section{References}

[1] Santos, J.F., Pulido-Calvo, I., Portela, M.M., Spatial and temporal variability of droughts in Portugal, Water Resources Research, 46, W03503, DOI:10.1029/2009WR008071, 2010a.

[2] Santos, J.F., Pulido-Calvo, I., Portela M.M., Variabilidade temporal e espacial das secas em Portugal Continental, $10^{\circ}$ Congresso da Água, APRH, Alvor, Portugal, 2010b.

[3] Santos, J.F., Portela, M.M., Pulido-Calvo I., Regional frequency analysis of droughts in Portugal, Water Resources Management, 25(14), 3537-3558, DOI 10.1007/s11269-0119869-z, 2011a.

[4] Santos, J.F., Portela, M.M., Pulido-Calvo, I., Regional Frequency Analysis of Droughts: Portuguese Case, International Conference on Ecohydrology and Climate Change, EcoHCC11 75, Tomar, Portugal, 2011b.

[5] Santos, J.F., Portela, M.M., Pulido-Calvo, I., Dimensionality reduction in drought modeling, Hydrological Processes, DOI:10.1002/hyp.9300, 2012a.

[6] Santos, J.F., Portela, M.M., Pulido-Calvo, I., Spring Drought Prediction based on winter teleconnection patterns and global SST in Portugal, Hydrologic Process (in press), 2012b.

[7] Santos, J.F., Portela, M.M.,. Quantificação de tendências em séries de precipitação mensal e anual em Portugal Continental, Seminário Ibero Americano sobre Sistemas de Abastecimento Urbano SEREA, Lisbon, Portugal, 2008.

[8] Guttman, N.B., Accepting the standardized precipitation index: a calculation algorithm, Journal of the American Water Resources Association 35: 311-322, 1999.

[9] McKee, T.B., Doesken, N.J., Kleist, J., The relationship of drought frequency and duration to time scales, in Proceedings of the 8th Conference on Applied Climatology, American Meteorology Society, 179-184, 1993.

[10] Santos, J.F., Portela, M.M., Caracterização de secas em bacias hidrográficas de Portugal Continental: aplicação do índice de precipitação padronizada, SPI, a séries de precipitação e de escoamento, $10^{\circ}$ Congresso da Água, APRH, Alvor, Portugal, 2010.

[11] Ntale, H.K., Gan, T., Drought indices and their application to East Africa, International Journal of Climatology, 23, 1335-1357, 2003.

[12] Vicente-Serrano, S.M., Spatial and temporal analysis of droughts in the Iberian Peninsula (1910-2000), Hydrological Sciences Journal, 51(1), 83-97, doi:10.1623/hysj.51.1.83, 2006a.

[13] Vicente-Serrano S.M., Las sequías climáticas en el valle medio del Ebro: Factores atmosféricos, evolución temporal y variabilidad espacial, in serie investigación 49, Publicaciones de Consejo de Protección de la Naturaleza de Aragón, Zaragoza, Spain, 2005. 
[14] Vicente-Serrano, S.M., Differences in Spatial Patterns of Drought on Different Time Scales: An Analysis of the Iberian Peninsula, Water Resources Management, Volume 20, Number 1, 37-60, DOI: 10.1007/s11269-006-2974-8, 2006b.

[15] Portela, M.M., Santos, J.F., Caracterização de secas por aplicação do índice de precipitação padronizada, SPI, a séries de precipitação e de escoamento: casos de estudo em Portugal Continental, XXIV Congresso LatinoAmericano de Hidráulica, Punta del Este, Uruguay, 2010.

[16] Agnew, C.T., Using the SPI to identify drought, Drought Network News, 12, 6-12, 2000.

[17] Portela, M.M., Santos, J.F., Naghettini, M., Matos, J.P., Silva, A.T., Superfícies de limiares de precipitação para identificação de secas em Portugal continental: uma aplicação complementar do Índice de Precipitação Padronizada, SPI. Recursos Hídricos, 33 (2), pp. 5-23, Associação Portuguesa dos Recursos Hídricos, APRH), Lisboa. DOI: 10.5894/rh33n2-1 (http://www.aprh.pt/rh/v33n2.html), 2012.

[18] Hosking, J.R.M., Fortran code written for inclusion in IBM research report RC20525, Fortran routines for use with method of L-moments, IBM Research Division, T.J. Watson Research Center, New York, USA, 1996. 